\title{
Atmospheric Plasma Jet: Effect of Inner Diameter Size to the Length of Plasma Discharge ${ }^{\dagger}$
}

\author{
Zulaika ABDULLAH ${ }^{1,2}$, Siti Khadijah ZAABA ${ }^{1,2, *}$, \\ Mohammad Taufiq MUSTAFFA ${ }^{3}$, Nor Aini SAIDIN ${ }^{4}$, \\ Johan Ariff MOHTAR ${ }^{5}$ and Ammar ZAKARIA ${ }^{1,2}$
}

\author{
${ }^{1}$ School of Mechatronics Engineering, Universiti Malaysia Perlis, Malaysia \\ ${ }^{2}$ Centre of Excellence for Advanced Sensor Technology, Universiti Malaysia Perlis, Malaysia \\ ${ }^{3}$ School of Manufacturing Engineering, Universiti Malaysia Perlis, Malaysia \\ ${ }^{4}$ Advanced Medical and Dental Institute, Universiti Sains Malaysia, Malaysia \\ ${ }^{5}$ Faculty of Engineering Technology, Universiti Malaysia Perlis, Malaysia
}

(Corresponding author's e-mail: khadijah@unimap.edu.my)

Received: 16 December 2017, Revised: 24 June 2018, Accepted: 24 July 2018

\begin{abstract}
The design of atmospheric plasma jet is basically using the combination of a noble gases, potential difference and a good dielectric material. In this work, we used quartz glass tube as a dielectric material with different inner diameter size to investigate the effect on the plasma discharge. We studied the changes of plasma discharge by observing the discharge lengths. We introduced a gas flow rate of 1000 $\mathrm{ml} / \mathrm{min}$ and maximum inner diameter of dielectric material of $10 \mathrm{~mm}$. Results showed that the discharge length are capable of reaching $30 \mathrm{~mm}$ and having various excited plasma species shown through optical emission spectrum.
\end{abstract}

Keywords: Atmospheric plasma jet, dielectric material, optical emission spectroscopy, reactive species

\section{Introduction}

Atmospheric plasma is a plasma in which the pressure approximately matches with the surrounding atmosphere [1]. Atmospheric plasma have found wide applications such as surface modification, inactivation of bacteria, food processing, dentistry and medical applications. Depending on required applications, there are a wide variety of plasmas generated under different conditions. There are few designs to set up the plasma. Recently, atmospheric plasma jet has been developed using a combination of a noble gases, potential difference and a good dielectric material. Atmospheric plasma jet is ionized gas that is generated at atmospheric pressure and at room temperature, by allowing the gas to flow in a small tube with the higher voltage supplied to the area [1]. Several gases commonly used in generating plasma are helium, argon and nitrogen. This is because they pose no harm to the environment or the human body when they are operated in an open manner [1].

Generally, free radicals such as the reactive oxygen species that exist in around plasma, can cause different effects. Reactive species generated through the electron impact excitation and dissociation in the higher pressure of the non-equilibrium plasma discharges, plays an important role in germicidal characteristics [2]. Both reactive oxygen species (ROS) and reactive nitrogen species (RNS) are the products from plasma excitation. Overproduction of ROS and RNS would damage the cell structure, including lipids, proteins and the DNA [2].

\footnotetext{
${ }^{\dagger}$ Presented at the $10^{\text {th }}$ International Conference on Plasma Science and Applications 2017: October $10^{\text {th }}-11^{\text {th }}, 2017$
} 
The reactive species can be identified by using an optical emission spectroscopy (OES). OES function is to capture the light emitted due to the de-excitation of atoms, molecules, ions and radicals that were previously excited and produced in the plasma discharge [3]. A spectrometer is a device that can be employed to measure the spectrum of plasma. The spectrometer consists of a monochromatic with several components to split or to separate and transmit a narrow portion of the optical signal, chosen from a wider range of wavelengths available at the input [3].

The light emitted by the plasma is focused by the fibre optic onto the monochromatic. The function of the fibre optic is to transmit radiation or images from one component to another [3]. The reactive species were identified by the value of the wavelength at each peak. More peak shows it have more reactive species.

Atmospheric plasma jet can be used in many applications especially in medical applications such as inactivation of cancer cells due to the presence of reactive species in the plasma that contribute to the cell death. This paper aims to analyse the effect of different inner diameter size of dielectric material in plasma generation on the length of plasma discharge. After that, the composition of plasma discharge is also studied using the best inner diameter size for plasma set up. The higher the length of plasma discharge and plasma composition, plasma generation will be optimized. Correlation between the length of plasma discharge and the plasma composition are also analysed.

\section{Methodology}

\section{Atmospheric plasma jet set up}

A dielectric material is one of the requirements to set up the atmospheric plasma jet. Choosing different inner diameter size of dielectric material gives different effect on the plasma discharge. It will change the length of the plasma discharge. This experiment used a quartz glass tube as the dielectric material. Four different inner diameters of quartz glass tube which are 1.5, 3, 5 and $10 \mathrm{~mm}$ shown in Figure 1 will be used to compare the length of plasma discharge. Plasma parameters such as type of gases used and flow rate of gases used will also be varied to get an optimize plasma generation. Helium, argon and nitrogen were used as the main working gas.

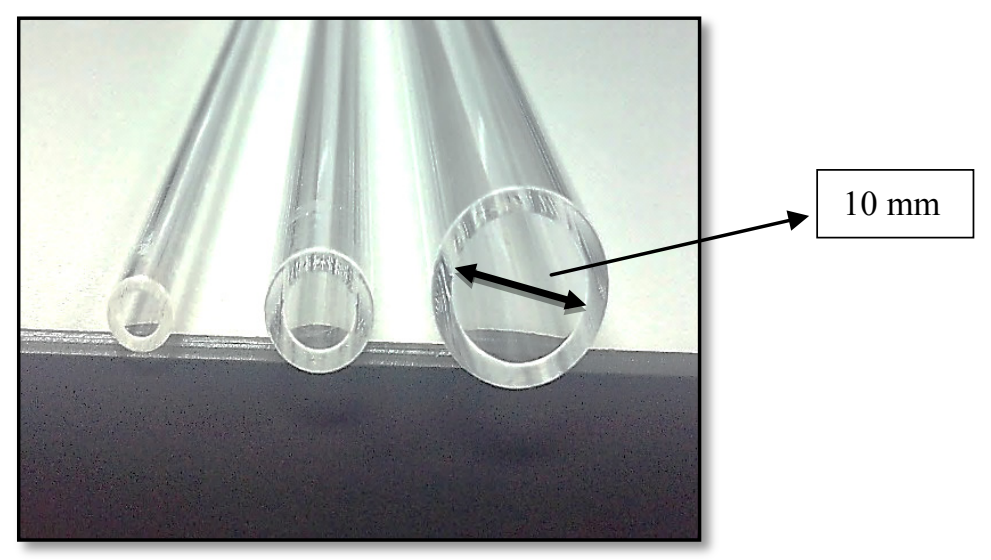

Figure 1 Example of different inner diameter size.

\section{Measurements length of plasma discharge}

The length of plasma discharge was measured starting from the mouth jet to the last tip of plasma discharge. The last tip of plasma discharge was recorded until it reached at the maximum time used which is $3 \mathrm{~min}$. The reading was repeated for 5 times to show its consistency. The measurement length of plasma discharge is shown in the Figure 2. 
http://wjst.wu.ac.th

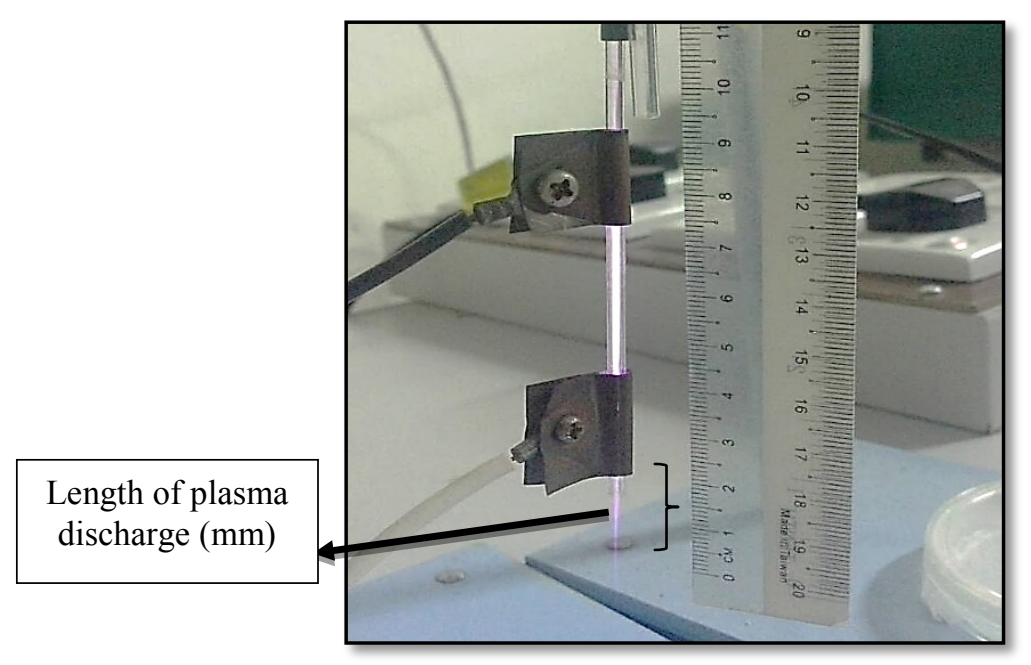

Figure 2 Length of plasma discharge.

\section{Optical Emission Spectroscopy (OES)}

An EPP200-UVN-SR-14 spectrometer, from STELLAR NET was used to evaluate the emission characteristics of the atmospheric plasma jet. This device has high resolution, within the range of $200 \mathrm{~nm}$ to $1100 \mathrm{~nm}$. This spectrometer was connected to a fibre optic (F600-Y-UV-SR-NIR), to collect the spectrum from the light of the plasma, then transfer it to the spectrometer. The Spectra Wiz OS software was used to analyse the spectrum graph [3].

The results, depicting the relative intensity of the emission peaks captured by spectrometer, help to identify the reactive species present in the plasma, based on the wavelength, which is plotted on the $\mathrm{x}$ axis. The types of chemical species that occur in the plasma can be related to the inactivation of bacteria. The fibre optic of the spectrometer was placed near the plasma plume at the static distance, $d$, as shown in Figure 3 and the measurements were taken for the working gas during different operation. The distance between the fibre optic and the plasma was $5 \mathrm{~mm}$.

The peaks of the spectral bands represented the reactive species or partial species in the plasma. The particle species in the plasma were identified based on the wavelengths. The National Institute of Standards and Technology (NIST, http://www.nist.gov/pml/data/asd.cfm) can be used as the reference source for identifying atomic species based on their peaks' wavelengths [3]. 


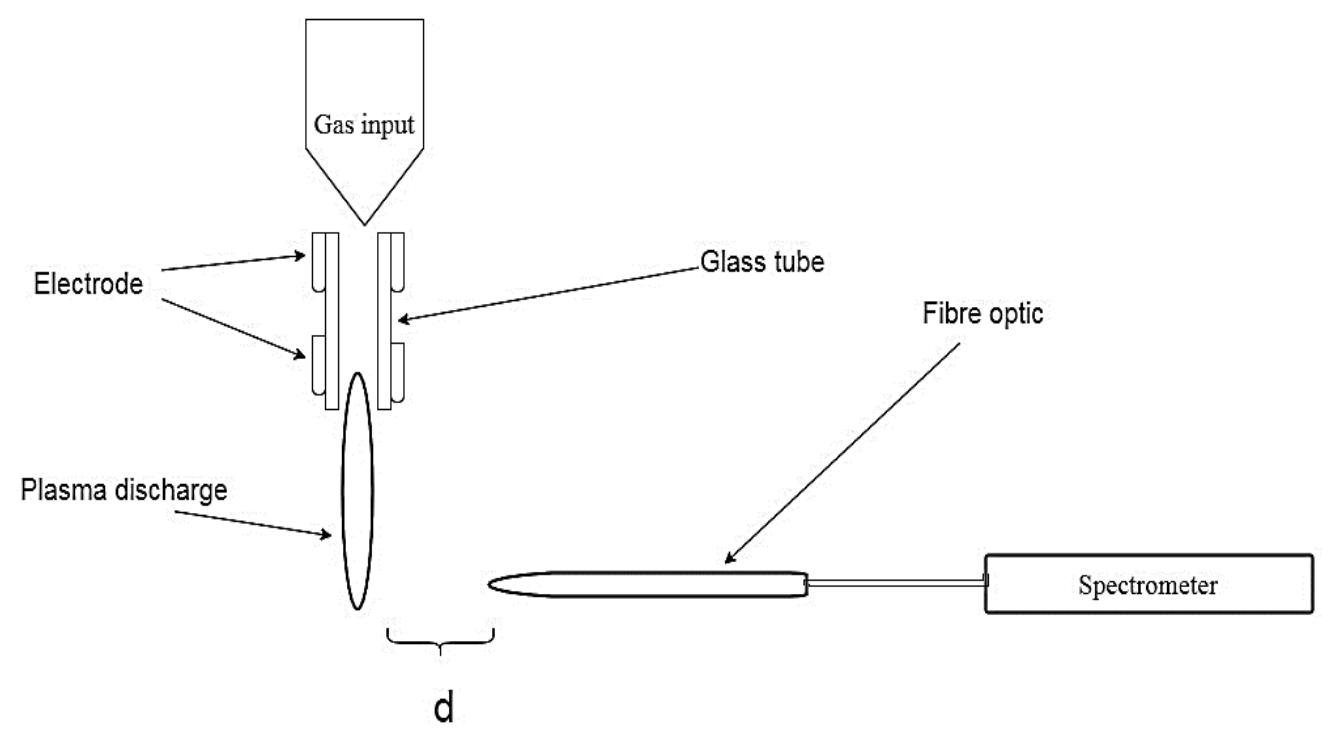

Figure 3 Schematic experimental setup for reactive species measurement by a spectrometer.

\section{Results and discussion}

Effect of different inner diameter size on length of plasma discharge

Table 1 Measurements on length of plasma discharge.

\begin{tabular}{|c|c|c|c|c|}
\hline No & $\begin{array}{l}\text { Inner diameter of quartz } \\
\text { glass Tube (mm) }\end{array}$ & $\begin{array}{l}\text { Type of gas } \\
\text { used }\end{array}$ & $\begin{array}{l}\text { Flow rate of gas } \\
\text { used }(\mathrm{ml} / \mathrm{min})\end{array}$ & $\begin{array}{c}\text { Maximum length of plasma } \\
\text { discharge }(\mathrm{mm})\end{array}$ \\
\hline \multirow{6}{*}{1} & \multirow{6}{*}{1.5} & \multirow{2}{*}{ Helium } & 400 & 10 \\
\hline & & & 1000 & 20 \\
\hline & & \multirow{2}{*}{ Argon } & 400 & 10 \\
\hline & & & 1000 & 20 \\
\hline & & \multirow{2}{*}{ Nitrogen } & 400 & 10 \\
\hline & & & 1000 & 20 \\
\hline \multirow{6}{*}{2} & \multirow{6}{*}{3} & \multirow{2}{*}{ Helium } & 400 & 15 \\
\hline & & & 1000 & 24 \\
\hline & & \multirow{2}{*}{ Argon } & 400 & 10 \\
\hline & & & 1000 & 22 \\
\hline & & \multirow{2}{*}{ Nitrogen } & 400 & 12 \\
\hline & & & 1000 & 20 \\
\hline \multirow{6}{*}{3} & \multirow{6}{*}{5} & \multirow{2}{*}{ Helium } & 400 & 10 \\
\hline & & & 1000 & 26 \\
\hline & & \multirow{2}{*}{ Argon } & 400 & 10 \\
\hline & & & 1000 & 25 \\
\hline & & \multirow{2}{*}{ Nitrogen } & 400 & 10 \\
\hline & & & 1000 & 24 \\
\hline
\end{tabular}




\begin{tabular}{ccccc}
\hline No & $\begin{array}{c}\text { Inner diameter of quartz } \\
\text { glass Tube (mm) }\end{array}$ & $\begin{array}{c}\text { Type of gas } \\
\text { used }\end{array}$ & $\begin{array}{c}\text { Flow rate of gas } \\
\text { used (ml/ min) }\end{array}$ & $\begin{array}{c}\text { Maximum length of plasma } \\
\text { discharge ( } \mathbf{m m})\end{array}$ \\
\hline \multirow{4}{*}{4} & Helium & 400 & 10 \\
4 & & $\mathbf{1 0 0 0}$ & $\mathbf{3 0}$ \\
& \multirow{3}{*}{10} & Argon & 400 & 10 \\
& & 1000 & 28 \\
& & 400 & 10 \\
& Nitrogen & 1000 & 26 \\
\hline
\end{tabular}

Table 1 shows the measurement on lengths of plasma discharge by using the different inner diameter of quartz glass tube, type of gas used and flow rate of gas used. The flow rate of gas used which are 400 and $1000 \mathrm{ml} / \mathrm{min}$ was chosen based on the minimum and maximum suitable flow rate gas for plasma generation using atmospheric plasma jet.

Atmospheric plasma was produced by combining the high voltage and a gas flowing into a quartz glass tube. Generating an atmospheric plasma is different for each gas. The length of plasma discharge were varied for every inner diameter size of quartz glass tube used. Regardless type of gas used for first inner diameter, $1.5 \mathrm{~mm}$, the maximum length of plasma discharge is $10 \mathrm{~mm}$ for flow rate $400 \mathrm{ml} / \mathrm{min}$ and $20 \mathrm{~mm}$ for flow rate $1000 \mathrm{ml} / \mathrm{min}$.

For inner diameter size of $3 \mathrm{~mm}$, the length of plasma discharge showed the longest length at 1000 $\mathrm{ml} / \mathrm{min}$ flow rate of helium used. For third inner diameter size, $5 \mathrm{~mm}$, initially the plasma discharge size conceded the inner diameter size. Then, after the discharge stabilises, the discharge narrows down and increased length. Their length were recorded after plasma discharge achieve its stability. By using helium at $1000 \mathrm{ml} / \mathrm{min}$ of flow rate used, the length of plasma discharge reach $26 \mathrm{~mm}$ length and it is the maximum length for this inner diameter size of quartz glass tube.

For the largest inner diameter size, $10 \mathrm{~mm}$, the length of plasma discharge has reached the maximum length which is $30 \mathrm{~mm}$ at $1000 \mathrm{ml} / \mathrm{min}$ of helium flow rate of gas used. For various field of atmospheric plasma applications, the optimum plasma parameters and also the plasma set up are the most important in order to have an optimized plasma treatment. From this experiment, it shows that the optimum parameters for plasma set up is at $1000 \mathrm{ml} / \mathrm{min}$ flow rate of helium used. By using the largest inner diameter size for quartz glass tube, $10 \mathrm{~mm}$, the length of plasma discharge for atmospheric plasma jet are capable to reach the maximum length. After that, the composition of plasma discharge for the best inner diameter size will be measured in order to analyse whether the plasma composition affect the length of plasma discharge.

\section{Composition of plasma discharge}

Atmospheric plasma exposure is a complex process, since there were multiple plasma particles such as ultraviolet (UV) excited species, ions or electron and others which can interact with any samples that being treated. The elements present in the atmospheric plasma jet emit certain wavelengths, which can be observed using an OES. An OES was used to investigate the intensity changes for plasma generated reactive species that are believed influence in plasma treatment especially in medical applications.

In the emission spectrum, spectral bands were observed in the ranges from $200 \mathrm{~nm}$ to $800 \mathrm{~nm}$, to investigate the behaviour of atoms and molecules and other constituent species. Due to the ionization and excitation that plasma undergoes in an open-air environment, it tends to produce certain types and number of the reactive species [3]. Identification of reactive species that are produced in the plasma is important in biological and medical applications in order to understand the interaction of plasma with living cells.

By using the largest inner diameter size of quartz glass tube which is $10 \mathrm{~mm}$, the elements present in the atmospheric plasma jet emit certain wavelengths. The optical emission spectrum shown in Table 2 was similar to those collected by several authors studying on the atmospheric plasma at cold temperature 
http://wjst.wu.ac.th

[4-6]. The table also compared the composition of reactive species in atmospheric plasma jet at 1000 $\mathrm{ml} / \mathrm{min}$ flow rate of gas using different in types of gas used.

An emission peak at a wavelength $290 \mathrm{~nm}$ was detected, but it is a very small one. The strongest emissions were observed in the 300 to $425 \mathrm{~nm}$ wavelength range, with nitrogen molecules dominating. Nitrogen $\left(\mathrm{N}_{2}\right)$ emission peaks have been observed at 295.5, 335.69, 356.10, 389.30, 500.34, 545.57, 666.42 and $726.69 \mathrm{~nm}$, while helium (He) emission peaks at 469.76 and $356.3 \mathrm{~nm}$. Oxygen molecules $\left(\mathrm{O}_{2}\right)$ were observed at 314.78, 374.46, 425.8 and $704 \mathrm{~nm}$. For medical applications, cancer treatment, oxygen molecules are very important roles in order to induce the apoptosis of cancer cell [9-12]. So that, many researchers had suggested to use the helium gas in atmospheric plasma set up for cancer treatments. Oxygen molecules tends to react as a redox chemotherapeutics in anti-cancer effects [9].

Table 2 Optical emission spectrum.

Type of gas




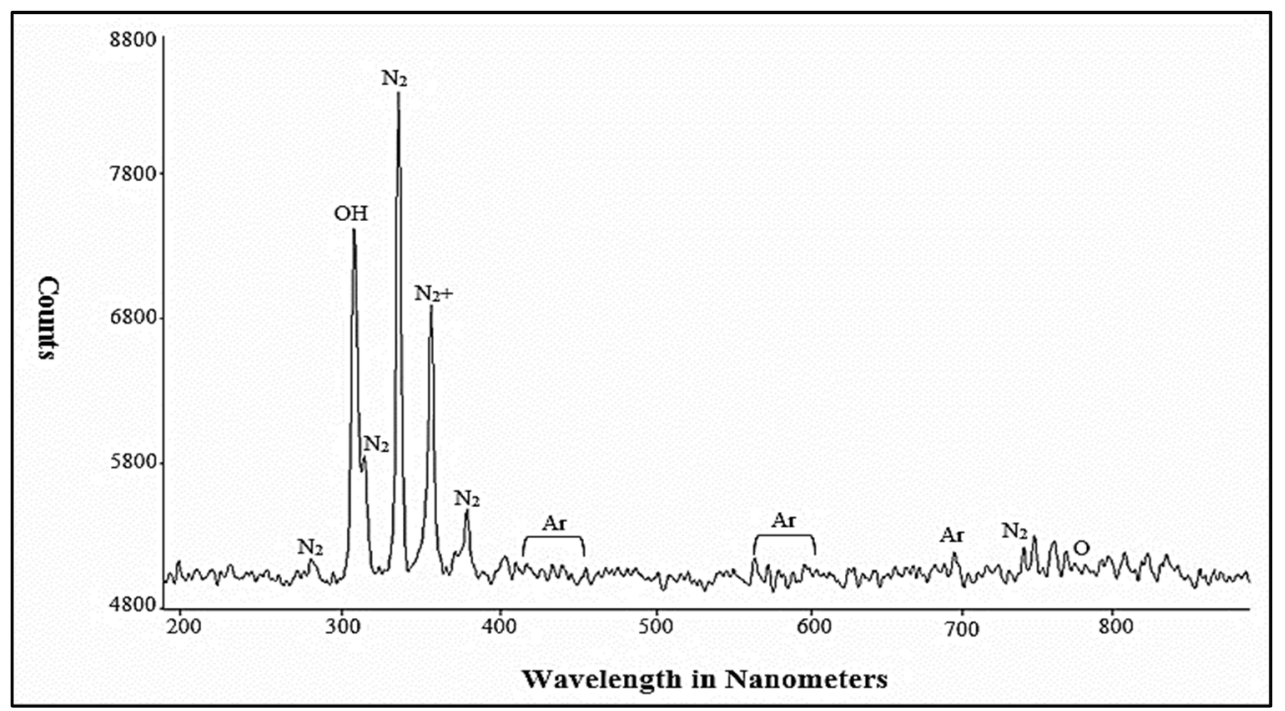

Nitrogen

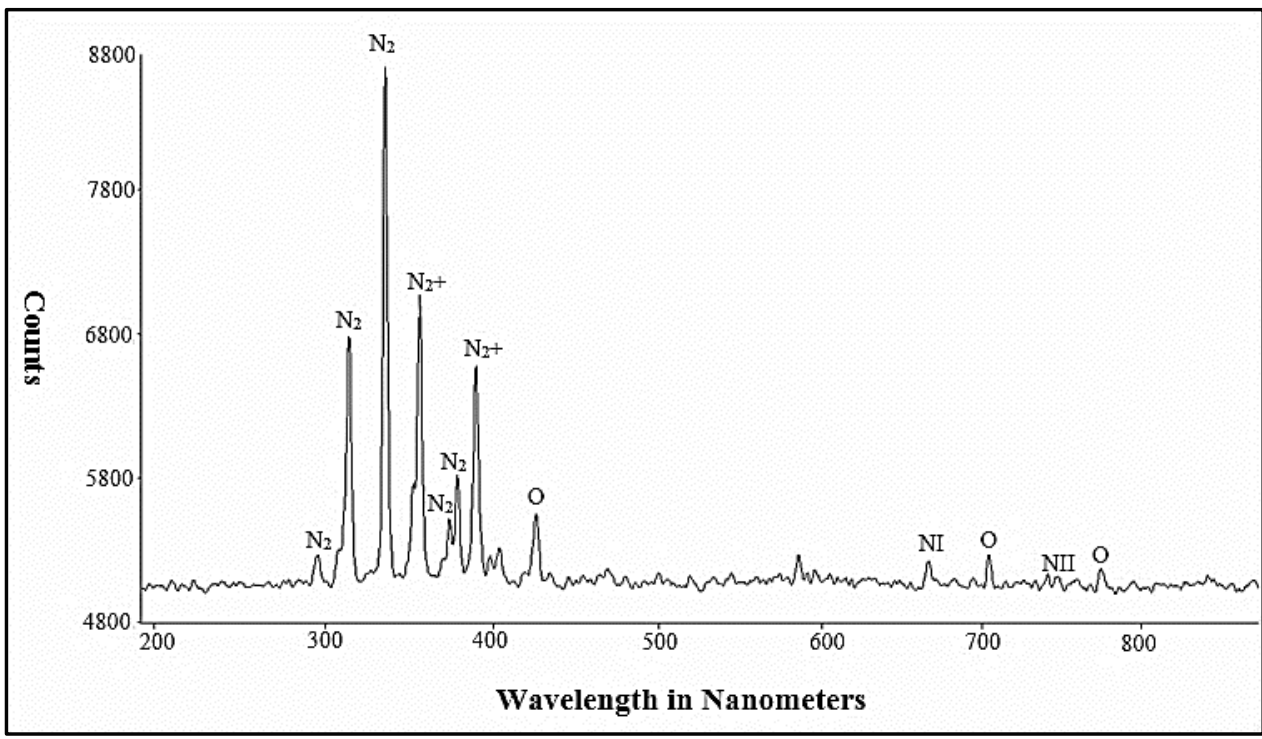

Based on Table 2, $\mathrm{N}_{2}$ was observed at wavelengths of line 295.3, 335.6, 378.39, 404.13 and 666.42 $\mathrm{nm}$. The $\mathrm{N}_{2}$ peaks appear at the same wavelengths for every gas flow rate. The major production processes of $\mathrm{N}_{2}$ species in a humid environment, are an electron induced process. Hydroxyl radical $(\mathrm{OH})$ peaks can be observed in the range of $260-310 \mathrm{~nm}$. In this experiment, the $\mathrm{OH}$ radicals' peaks were observed at the wavelength of $309 \mathrm{~nm}$ in the emission spectrum. The $\mathrm{OH}$ radicals observed in the spectrum has been generated from the reaction between the electrons in the plasma and the $\mathrm{H}_{2} \mathrm{O}$ molecules in the air.

The $\mathrm{OH}$ is the product of the interaction of the $\mathrm{O}_{2}$ gas. $\mathrm{O}_{2}$ also produces $\mathrm{O}, \mathrm{OH}$ and mixture of radicals that contribute to the medical applications. Among these radicals, $\mathrm{OH}$ is considered the most efficient especially in cancer treatments [9]. OH radicals are most effective at inducing the apoptosis of 
http://wjst.wu.ac.th

cancer cell. $\mathrm{OH}$ radicals can induce the host defence genes in cell activity and also can damage the DNA strand of cell [9]. Commonly, the production of reactive species can affect the cell growth and causes the oxidative stress that contributes to the inactivation of cancer cell [9-12]. Reactive species inflict significant damage to the cells through reactions with various micromolecules [8]. In cancer treatment, plasma production effect on the cancer cell while treatment [9]. Reactive species also can react directly with proteins and modify them to change the protein structure [8].

Our result showed that the atmospheric plasma jet produced multiple reactive species such as $\mathrm{N}_{2}$, $\mathrm{O}_{2}, \mathrm{OH}, \mathrm{He}$ and Ar. Helium with higher flow rate have multiple reactive species compared to other type of gases used. This can help researchers in developing a new treatment in plasma applications with the optimum parameters. The result also shows that the plasma composition correlated to the length of plasma discharge because the longer the length of plasma discharge, the more plasma composition.

\section{Conclusions}

Based on the results, the type of gases, the flow rate of gases used and the inner diameter size of quartz glass tube are important in atmospheric plasma jet set up. Optimization of plasma generation can be achieved by using helium with flow rate at $1000 \mathrm{ml} / \mathrm{min}$ as working gas. This can be applied in plasma applications especially in medical applications. Our experimental results strongly suggest that the atmospheric plasma jet as a promising tool in plasma applications because it is capable to reach $30 \mathrm{~mm}$ in length and also contains various reactive species that can be essentially in plasma applications. For atmospheric plasma jet set up, the higher flow rate of gas used and the bigger inner diameter size of quartz glass tube will produce a better plasma discharge.

\section{Acknowledgements}

The author would like to acknowledge the support from the Fundamental Research Grant Scheme (FRGS) under a grant number of FRGS/1/2015/SG02/UNIMAP/02/5 from the Ministry of Higher Education Malaysia.

\section{References}

[1] L Bárdos and H Baránková. Cold atmospheric plasma: Sources, processes, and applications. Thin Solid Films 2010; 518, 6705-13.

[2] C Hoffmann, C Berganza and J Zhang. Cold atmospheric plasma: Methods of production and application in dentistry and oncology. Med. Gas Res. 2013; 3, 1-15.

[3] US Solutions. StellarNet Miniature Spectrometer Manual CC Declaration of Conformity. New Jersey, USA, 2011, p. 1-53.

[4] HS Uhm, EH Choi, GS Cho and DH Hwang. Atmospheric pressure nitrogen plasma jet: Observation on striated multilayer discharges patterns. Appl. Phys. Lett. 2008; 93, 14-7.

[5] Q Xiong, X Lu, K Ostrikov, Z Xiong, Y Xian, F Zhou, C Zou, J Hu, W Gong and Z Jiang. Length control of He atmospheric plasma jet plumes: Effects of discharge parameters and ambient air. Phys. Plasmas 2009; 16, 1-6.

[6] N Jiang, A Ji and Z Cao. Atmospheric pressure plasma jet: Effect of electrode configuration, discharge behavior, and its formation mechanism. J. Appl. Phys. 2009; 106, 1-7.

[7] X Lu, GV Naidis, M Laroussi, S Reuter, DB Graves and K Ostrikov. Reactive species in nonequilibrium atmospheric-pressure plasmas: Generation, transport, and biological effects. Phys. Rep. 2016; 630, 1-84.

[8] JS Sousa and V Puech. Diagnostics of reactive oxygen species produced by microplasmas. J. Phys. D: Appl. Phys. 2013; 46, 464005.

[9] X Yan, F Zou, S Zhao, X Lu, Z Xiong, Q Xiong, P Deng, J Huang and G Yang. On the mechanism of plasma inducing cell apoptosis. IEEE Trans. Plasma Sci. 2010; 38, 2451-7.

[10] HS Uhm, EH Choi, GS Cho and DH Hwang. Influence of reactive oxygen species on the sterilization of microbes. Curr. Appl. Phys. 2013; 13, 30-5. 
http://wjst.wu.ac.th

[11] WH Chung. Mechanisms of a novel anticancer therapeutic strategy involving atmospheric pressure plasma-mediated apoptosis and DNA strand break formation. Arch. Pharm. Res. 2016; 39, 1-9.

[12] P Jawaid, MU Rehman, QL Zhao, K Takeda, K Ishikawa, M Hori, T Shimizu and T Kondo. Helium-based cold atmospheric plasma-induced reactive oxygen species-mediated apoptotic pathway attenuated by platinum nanoparticles. J. Cell. Mol. Med. 2016; 20, 1737-48. 